\title{
THREE-DIMENSIONAL NUMERICAL SIMULATION OF A VERTICAL THERMAL TANK
}

\begin{abstract}
G. A. A. Moreira ${ }^{a}$,
A. Barbosa ${ }^{\text {, }}$

A. L. Viana', and R. M. Valle ${ }^{\mathrm{c}}$

${ }^{a}$ Universidade Federal do Paraíba Departamento de Engenharia de Energias Renováveis

Centro de Energias Alternativas e Renováveis

Bairro Cidade Universitária

CP. 5115, João Pessoa, Paraíba, Brasil gilberto@cear.ufpb.br

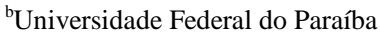
Departamento de Engenharia Mecânica Centro de Tecnológia

Bairro Cidade Universitária

CP. 5115, João Pessoa, Paraíba, Brasil

${ }^{\mathrm{c}}$ Universidade Federal do Paraíba Departamento de Engenharia de Energias Renováveis

Centro de Energias Alternativas e Renováveis

Bairro Cidade Universitária

CP. 5115, João Pessoa, Paraíba, Brasil dUniversidade Federal de Minas Gerais Departamento de Engenharia Mecânica Belo Horizonte, Minas Gerais, Brasil

\section{ABSTRACT}

In this study, the results obtained by the numerical simulation presented in this paper are compared with the results obtained experimentally by Oliveski (2000) for a vertical cylindrical thermal reservoir with internal diameter of $0.42 \mathrm{~m}$ and internal height of $0.57 \mathrm{~m}(79 \mathrm{~L})$. In the simulation using Ansys software, for the same parameters of the problem, a study to evaluate the degree of mesh refinement was performed based on the methodology used by Adolfo (2015). The boundary conditions adopted were: Flow: Transient; Buoyancy Model: Boussinesq Approximation; Step of time used: 1s; Wall Condition: Top Non slip / adiabatic; Base: $\mathrm{h}=06$ $[\mathrm{Wm} \wedge 2 / \mathrm{K}]$; Lateral: $\mathrm{h}=10[\mathrm{Wm} \wedge 2 / \mathrm{K}]$; Initial tank conditions: Null velocity field and initial temperature of approximately $355.15 \mathrm{~K}$. Total simulated flow time: $18,000 \mathrm{~s}$. For the external temperature, contour condition used in the simulation, the ambient temperature was used as a function of time through the graph provided by Oliveski. Three meshes were compared based on the methodology used by Adolfo (2015) in his studies. These have 1,512,143 and 7,997,663, 851,837 and 4,379,079, 271,898 and $1,308,368$, number of nodes and elements, respectively. For the turbulence model adopted, the SST (Shear Stress Transport) model was used. The simulations took approximately 58 days to complete. The residue sought in the iterations was at least 0.001 , with a maximum of 100 iterations for each time step. For the behavior of the temperature field in the tank over time the formation of the stratified temperature profile was observed, as described in Oliveski's work, and also that the thermal stratification occurs only in the lower region and that in the upper region the water becomes temperature is almost constant. In terms of mean temperature in the tank, the simulation is very close to the results shown by Savicki (2007). However, in terms of temperature profile along the height of the tank, this behavior is shown to be different. Another fact is that the height of the thermocline found in this simulation was considerably higher than that shown in the Savicki simulation. Therefore, the results obtained were validated with the experimental results presented by Oliveski and the numerical results presented by Savicki. It has been confirmed that the mesh with the second refinement level is already sufficiently capable of generating satisfactory results.
\end{abstract} ramon@demec.ufmg.br

Received: January 30, 2020 Revised: February 20, 2020 Accepted: March 20, 2020
Keywords: thermal reservoirs; numerical simulation; computational grid; thermal stratification

\section{NOMENCLATURE}

A Area, $\mathrm{m}^{2}$

g gravity acceleration constant, $\mathrm{m} / \mathrm{s}^{2}$

h enthalpy, $k J / k g$

p pressure, $\mathrm{N} / \mathrm{m}^{2}$

$\mathrm{P} \quad$ dimensionless pressure

Q overall heat transfer rate, $\mathrm{W}$

q" heat transfer flux, $\mathrm{W} / \mathrm{m}^{2}$

s entropykJ/kg

$\mathrm{t} \quad$ time, $\mathrm{s}$

$\mathrm{T} \quad$ average fluid temperature, $\mathrm{K}$

$\mathrm{u}, \mathrm{v}, \mathrm{w} \quad$ velocity components, $\mathrm{m} / \mathrm{s}$

$\mathrm{x}, \mathrm{y}, \mathrm{Z} \quad$ cartesian coordinates, $\mathrm{m}$

$\mathrm{X}, \mathrm{Y}, \mathrm{Z}$ dimensionless cartesian coordinates

\section{Greek symbols}

$\beta \quad$ thermal expansivity, $1 / \mathrm{K}$

$\varepsilon \quad$ Exergy, $k J$

$\rho$ density, $\mathrm{kg} / \mathrm{m}^{3}$

$\Omega \quad$ tank volume, $\mathrm{m}^{3}$

$\xi \quad$ availability of each control volume, $\mathrm{kJ} / \mathrm{kg}$

\section{Subscripts}

0 reference state

s solid wall and fin material

$\infty \quad$ free stream 


\section{INTRODUCTION}

Currently, research on the optimization of equipment for obtaining solar energy has been gaining more and more space in the scientific environment, however, besides developing research related to equipment that capture solar radiation directly as solar collectors and photovoltaic panels, studies with in relation to the storage processes of this thermal energy, that is, regarding the optimization of thermal storage, are also extremely necessary in view of some differences between the moment the working fluid is heated by solar radiation and the moment of its use. Therefore, it is very important to know the behavior of the temperature inside the thermal reservoir in order to obtain a good functioning of liquid heating systems through solar energy.

Through the use of numerical simulations, it is possible to know these behaviors within these systems. The simulations concern a tool that faithfully reproduces physical phenomena that occur in the installation, allowing the time savings in empirical tests, deep analysis of the equipment in order to obtain accurate and important data to the project. However, for these numerical simulations the use of a good computational mesh is an essential factor so that the results and the behaviors required within these equipments can be quantified in the best possible way.

This work aims to compare the results provided by the numerical simulation presented in this work with the results obtained experimentally by Oliveski for a vertical cylindrical thermal reservoir of identical dimensions, geometry and operating conditions, as well as to verify through a mesh study the degree of refinement of the most suitable computational mesh so that it can present as precise results as those of much more refined meshes that would require a greater computational effort in its uses.

\section{REVIEW}

\section{Storage Tanks and Thermal Stratification}

According to Oliveski (2000), the temperature distribution in the reservoir plays a fundamental role in the natural circulation that occurs throughout the system. As Pentagna et al. (2003) explain in their work, "Thermal stratification is understood in this context as the temperature distribution where the thermal gradient exists almost vertically." The correct identification of the isocline, the thin layer of fluid separating the cold layer from the layer hot in the tank and having a large temperature gradient between the top and the bottom of the tank as well as its position along the height of the tank at known time intervals is of vital importance for the correct evaluation of the energy availability. Only in this way is it possible to fill a known energy demand, keeping constant the maximum and minimum temperature levels of the working fluid ".

Over the years, many papers have been published on the process of energy storage through the thermal stratification of a fluid in an isolated tank of the medium. In 1977, Lavan and Thompson conducted an experimental study on thermally stratified hot water storage tanks. Relationships with different lengths and diameters, mass flow rates and inlet and outlet temperatures were made in the experiments and the authors were able to produce several useful relationships for storage system designs.

Kleinbach, Beckman and Klein (1993), through the comparison of results of storage tank models with experimental data, concluded that the stratification depends mainly on the volume of the tank, the design of the input and output instruments and the inflow and output.

Ismail et al. (1996), in a study of thermally stratified tanks for hot and cold-water storage applications, established a two-dimensional model, based on equations of mass conservation, amount of movement and energy to represent thermal transport processes in the tank. The obtained results were compared with available experimental results and also with a one-dimensional analytical model.

Rosen (2001) verified the energy and exergy content in thermal storage of stratified liquid using six different models of temperature distribution. Knowing Rosen that factors such as precision of the results and computational effort are involved in the choice of a particular distribution, for each of the models of temperature distribution used was shown its relation with the formation of the thermal stratification, with the energy storage efficiency and with its exergy storage capacity. In this way, it was possible that the results obtained by the exergy analysis contributed to the design and analysis of thermal storage systems.

Ievers (2009) studied through numerical and experimental simulations the influence of the storage volume and hot water inlet position on the thermal stratification of vertical cylindrical water storage tanks. It also analyzed the behavior of the temperature profile along the height of the tank in order to indicate the evolution of tank heating and discusses in its article different methods recommended in the literature in order to quantify the thermal stratification of storage tanks. In the same paper, Ievers also chose the model that was proposed by Rosen (2001), which compares the level of stratification of the tank with the exergy within the tank, as analyzed.

According to Adolfo (2015), the process of mixing water inside the tank is a process that generates entropy through the mixing of fluids of different temperatures and energy losses to the medium. As a consequence, this process ends up degrading the energy stored by the tank and this, in 
turn, loses the quality of its thermal stratification. According to Rosen, the instantaneous exergy of the storage tank $\varepsilon$ given in $[\mathrm{kJ}]$ is defined by:

$$
\varepsilon=\int_{\Omega}^{1} \xi \rho \mathrm{d} \Omega
$$

Where $\rho$ is the density of the control volume, given in $\left[\mathrm{kg} / \mathrm{m}^{3}\right], \Omega$ is the tank volume given in $\left[\mathrm{m}^{3}\right]$ and $\xi$ is the availability of each control volume given in $[\mathrm{kJ} / \mathrm{kg}]$ which can be calculated by:

$$
\xi=\left(h-h_{0}\right)-T_{0}\left(s-s_{0}\right)
$$

Where $\mathrm{h}$ is the enthalpy and h0 is the enthalpy in the reference state, given in $[\mathrm{kJ} / \mathrm{kg}], \mathrm{s}$ is the entropy and s0 is the entropy in the reference state, given in $[\mathrm{kJ} / \mathrm{kg} \mathrm{K}]$, and $\mathrm{T} 0$ is the temperature in the reference state, given in [K].

Rosen (2001) also defined a dimensionless parameter based on exergy $\zeta$ capable of quantifying the degree of thermal stratification of a tank by comparing two ideal opposite cases: a perfectly stratified tank and a perfectly mixed tank. According to Adolfo (2015), perfectly mixed tank is one in which the temperature of each control volume inside the tank observed at random has the same temperature, that is, where the heating of the same occurs perfectly homogeneous and the total volume of liquid inside it undergoes heating without ever a region heating more or less than the others. The perfectly stratified tank, however, is one in which there is no mixing between fluids of different temperatures.

\section{Natural convection}

According to Incropera et al. (2008), heat transfer (or heat) is the thermal energy in transit due to a difference in temperature in space. Of the three modes of heat transfer (convection, conduction, and radiation), convection is the mode in which heat transfer occurs between a surface and a moving fluid at different temperatures.

The mode of heat transfer by convection comprises in addition to the transfer of energy due to random molecular motion (diffusion), the global movement of the fluid, also called advection. This is associated with the fact that the collective motion of a large number of molecules, in the presence of a temperature gradient, contributes to the heat transfer.

Also, according to Incropera et al, heat transfer can be classified in relation to the nature of the fluid flow. Convection will be forced when the flow is caused by external means, and free (or natural) when the flow of the fluid is induced by forces of buoyancy, which are originated from differences in densities (specific masses) caused by temperature variations in the fluid.

The equation describing the rate of heat transfer by convection, known as the law of Newton's cooling, is given by:

$$
q^{\prime \prime}=h A\left(T_{s}-T_{\infty}\right)
$$

where:

$\mathrm{T}_{\mathrm{s}}=$ Surface Temperature

$\mathrm{T}_{\infty}=$ Fluid Temperature

$\mathrm{h}=$ Coefficient of heat transfer by convection, in $\mathrm{W} /\left(\mathrm{m}^{2} \cdot \mathrm{K}\right)$

The rate of heat transfer through the wall can be found by:

$$
\dot{Q}=h A\left(T_{s}-T_{\infty}\right)
$$

where:

A = Solid surface heat exchange area

The convection heat transfer coefficient (h) is a function of a large number of variables, such as fluid transport properties (viscosity, density, thermal conductivity), fluid velocity, contact geometry, among others. However, this empirical parameter, besides being obtainable through Newton's law of cooling, can be found through the use of correlated dimensionless parameters, such as Nusselt $(\mathrm{Nu})$, Reynolds (Re) and Prandtl (Pr) numbers. flow. Many correlations are obtained in the literature, but the accuracy of the results of these correlations in the determination of the convection coefficient will depend on the type of application to which they are intended, because the flows have different characteristics.

The use of dimensionless numbers in the equations that govern the study of natural convection becomes appropriate considering that these are in general complex and knowing the behavior of fluid flows in cavities with natural convection by means of dimensionless numbers make them more simplified.

In 1967 Evans et al carried out analytical and experimental studies of natural convection in vertical cylinders where a cylinder was partially filled with liquid and subjected to a uniform heat flow in the walls. The variation of several important parameters, such as the test liquid, the liquid depth, the wall heat flux beyond the extensive range of Prandtl numbers of 2 to 8,000 , the $L / D$ ratio of 1 to 3 and of the Grashof number from 103 to 1011 for laminar and turbulent flow regimes was performed and through the use of thermocouples and dye markers it was possible to measure the temperature field within the liquid by evaluating the existing flow patterns. The authors, in addition to verifying that the core fluid temperature varies only in the vertical direction (not in the horizontal direction), have developed an analytical model that can be used with a step-by-step 
computational procedure to predict the temperature distribution in the fluid as a function of time for an arbitrary set of conditions, finally validating it with experimental studies.

GUO et al. (1985), investigating the flux and temperature stratification in a liquid thermal storage tank for a solar energy system, have been able to develop a two-dimensional, time-dependent mathematical model based on the principles of heat transfer by natural and forced convection. They presented numerical results on flow and temperature distribution patterns in a liquid storage tank for very large Grashof and Reynolds numbers, along with the numerical scheme.

Truman and Wildin (1989) were able to solve a model for hot liquid storage tanks using the finite difference technique. Such a simple and efficient model was compared with an experimental model so that the distributions of temperatures in the water and the flow of energy between the tank were satisfactorily quantified.

Oliveski, Krenzinger and Vielmo (2003) have developed a numerical and experimental study on velocity and temperature fields within a thermal storage tank subjected to natural convection with thermal losses to the environment by the side wall, top and base. The numerical simulation is done with 3 versions of the Multi-node model (onedimensional) and with a two-dimensional model that uses the conservation equations of mass, momentum and energy discretized by the finite volume method. For the validation of the numerical models 40 different tank configurations were performed, varying aspect ratios, insulation thicknesses and volumes.

\section{Fluid mechanics and computational modeling}

The problems of fluid mechanics concerning the movement and transport of particles can be represented by the Continuity Equation and the Navier-Stokes Equation. In addition, for problems involving heat exchanges, the Energy Conservation Equation is also used. Such control equations developed for the whole system can be written as follows:

Continuity Equation:

$$
\left(\frac{\partial \rho}{\partial t}+\frac{\partial(\rho u)}{\partial x}+\frac{\partial(\rho v)}{\partial y}+\frac{\partial(\rho w)}{\partial z}\right)=0
$$

Momentum Equation:

$$
\begin{aligned}
& \left(\frac{\partial(\rho u)}{\partial t}+\frac{\partial(\rho u u)}{\partial x}+\frac{\partial(\rho v u)}{\partial y}+\frac{\partial(\rho w u)}{\partial z}\right)= \\
& -\frac{\partial P}{\partial x}+u\left(\frac{\partial^{2} u}{\partial x^{2}}+\frac{\partial^{2} u}{\partial y^{2}} \frac{\partial^{2} u}{\partial z^{2}}\right)
\end{aligned}
$$

$$
\begin{aligned}
& \left(\frac{\partial(\rho v)}{\partial t}+\frac{\partial(\rho u v)}{\partial x}+\frac{\partial(\rho v v)}{\partial y}+\frac{\partial(\rho w v)}{\partial z}\right)= \\
& -\frac{\partial P}{\partial y}+u\left(\frac{\partial^{2} v}{\partial x^{2}}+\frac{\partial^{2} v}{\partial y^{2}} \frac{\partial^{2} v}{\partial z^{2}}\right) \\
& \left(\frac{\partial(\rho w)}{\partial t}+\frac{\partial(\rho u w)}{\partial x}+\frac{\partial(\rho v w)}{\partial y}+\frac{\partial(\rho w w)}{\partial z}\right)= \\
& \rho g \beta\left(T-T_{\infty}\right)+u\left(\frac{\partial^{2} w}{\partial x^{2}}+\frac{\partial^{2} w}{\partial y^{2}} \frac{\partial^{2} w}{\partial z^{2}}\right)
\end{aligned}
$$

Energy Equation:

$$
\begin{aligned}
& \left(\frac{\partial(\rho c T)}{\partial t}+\frac{\partial(\rho c u T)}{\partial x}+\frac{\partial(\rho c v T)}{\partial y}+\frac{\partial(\rho c w T)}{\partial z}\right)= \\
& \rho\left(\frac{\partial^{2} T}{\partial x^{2}}+\frac{\partial^{2} T}{\partial y^{2}} \frac{\partial^{2} T}{\partial z^{2}}\right)
\end{aligned}
$$

There are problems in the mechanics of fluids in which many physical equations are involved and the complexity of the analytical treatment becomes very expensive or infeasible. Some simplifications in terms of the variables involved or space-domain dimensionality can guarantee the continuity of the search for the analytical solution in such situations, or even facilitate the search for a simplified numerical solution. The latter occurs mainly when it is not so relevant what happens within each space of a domain, but in the domain as a whole. This is what happens when one starts with the use of techniques of integral analysis of control volumes. However, it is often necessary to know what happens within a particular domain space and a differential approach must be used. One of the ways of solving this type of problem is the finite volume method (MVF) in order to find results numerically. This method is widely used by CFD (Computational Fluid Dynamics) software and is increasingly flexible and with better resources to work with. The Finite Volume Method is defined as the integration in space and time of the differential equation in the conservative form in one of the control volumes, Patankar (1980). This method uses the differential equation in its integral form and for this, the discretization of the domain of the studied problem becomes extremely necessary. When solving a system of partial differential equations, the boundary conditions, together with the initial conditions, determine the particular solution of the problem being studied.

\section{Time and Mesh Study}

The discretization of the studied domain is a very important step of numerical simulation by the Finite Volume Method (MVF), considering that the 
higher the level of refinement the greater the precision of the numerical results, however the computational effort is also higher; and vice versa. It is also known that there is a refinement level of domain discretization where major refinements do not significantly change the results sought. The search for this level of acceptable refinement culminates in the so-called mesh independence, a name commonly given to the finite volume mesh that forms the discretized domain. This method consists in increasing the resolution of the coarser initial mesh, repeating the simulation with this new, more refined mesh and verifying if there was a significant change of results between the two meshes. If this variation of results is confirmed, thus indicating that the mesh is not adequate, this process must be repeated until relatively small variations of results are achieved (generally of the order of $1 \%$ ), thus indicating the achievement of a independent solution of mesh and therefore, a converged mesh (Siqueira, 2014).

Adolfo (2015) conducted a time independence of meshes and applied the ASME VV20 Standard for numerical simulations of fluid dynamics to analyze a vertical cylinder in order to compare and validate the results obtained by Ievers. An important fact in this study was that the levels of refinements used were much higher than the level of refinement used by Ievers. In addition, it was considered a permanent flow study for the tank walls at a fixed temperature of $300 \mathrm{~K}$, so that there is loss of heat to the walls as soon as the hot water enters the tank. For buoyancy modeling, the Boussinesq approximation was used to calculate the specific mass of water, while for the other properties water was considered as Newtonian fluid. Gravity was adopted $9.8 \mathrm{~m} / \mathrm{s}^{2}$ from the top to the bottom of the tank.

With the analysis of the errors between

measurements in each of the six meshes studied and with the results obtained through the application of ASME VV 20, which helps to quantify the precision of the results obtained for each mesh facilitating the choice by the level of refinement of each problem , Adolfo came to the conclusion that mesh number 3 already had sufficient refinement to provide flow data with similar accuracy to what more refined meshes (numbers 4, 5 and 6) would provide.

In a transient flow, it is necessary to choose a suitable time step to obtain the flow data over time. Very small-time steps may reveal greater details of the flow at the cost of a long computational time, whereas larger time steps can save large simulation time while it may compromise the flow properties sought. The ideal time step is therefore the one from which, by adopting smaller time steps, the difference in flow properties is irrelevant. By also carrying out a study for Adolfo time step independence, adopting the same boundary conditions as the original Ievers simulation with adiabatic tank walls, he observed that the results for the flow properties showed great convergence already from the step of time of $0.5 \mathrm{~s}$, original value taken by Ievers in their simulation.

\section{METHODOLOGY}

Oliveski et. al. (2000), developed an experimental study and numerical simulations regarding the cooling process of vertical thermal reservoirs. In order to validate the methodology used in the computational simulation for the air conditioning project of the LES-UFPB, a computer simulation was performed using Ansys software using the same tank geometry as the main operating conditions used in the cited study. In addition, a comparative study was carried out for the three meshes with different levels of refinement and for the same parameters based on the methodology used by Adolfo (2015). The results were then compared with the experimental results obtained by Oliveski.

The tank studied has an internal diameter of $0.42 \mathrm{~m}$ and an internal height of $0.57 \mathrm{~m}$, giving a total internal volume of approximately 79L. For two cases investigated by Oliveski, called fast cooling and slow cooling, the reservoir is disconnected from the rest of the system's hydraulic circuit and thus there is no water inlet or outlet from the solar collectors or the cold-water reservoir. At the bottom of the shell there is a wooden base of $30 \mathrm{~mm}$ followed by a layer of 90 $\mathrm{mm}$ glass wool. In the upper region there is a $10 \mathrm{~mm}$ expanded polystyrene layer followed by a layer of $120 \mathrm{~mm}$ glass wool. The figure below shows in detail the geometry of the tank with its main dimensions.

The two heat transfer regimes are differentiated by the fact that in the first case, rapid cooling, only the bottom and top of the reservoir are isolated, the side of the tank being fully exposed at room temperature. Already in the second case, slow cooling, an insulation layer is placed on the side wall of the tank. Figures 1and 2 present the main dimensions as well as the materials used for lateral, top and base insulation during the experiment conducted by Oliveski.

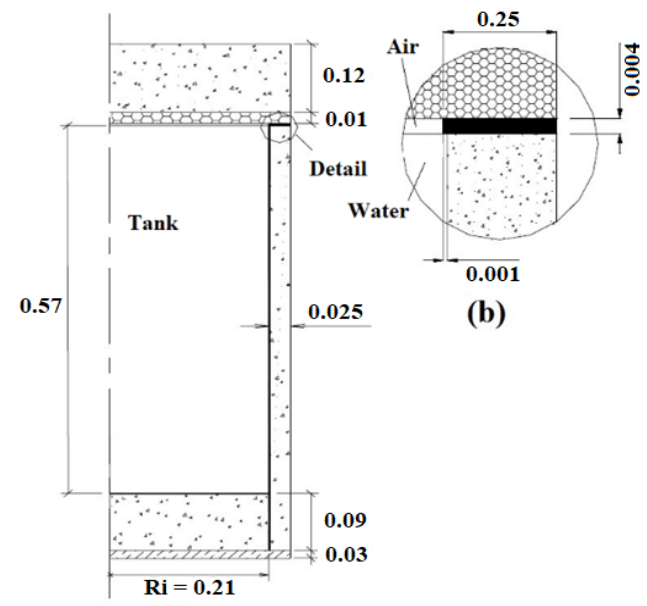

(a)

Figure 1. (a) Tank and insulation dimensions; (b) Detail of the Upper Flap. 


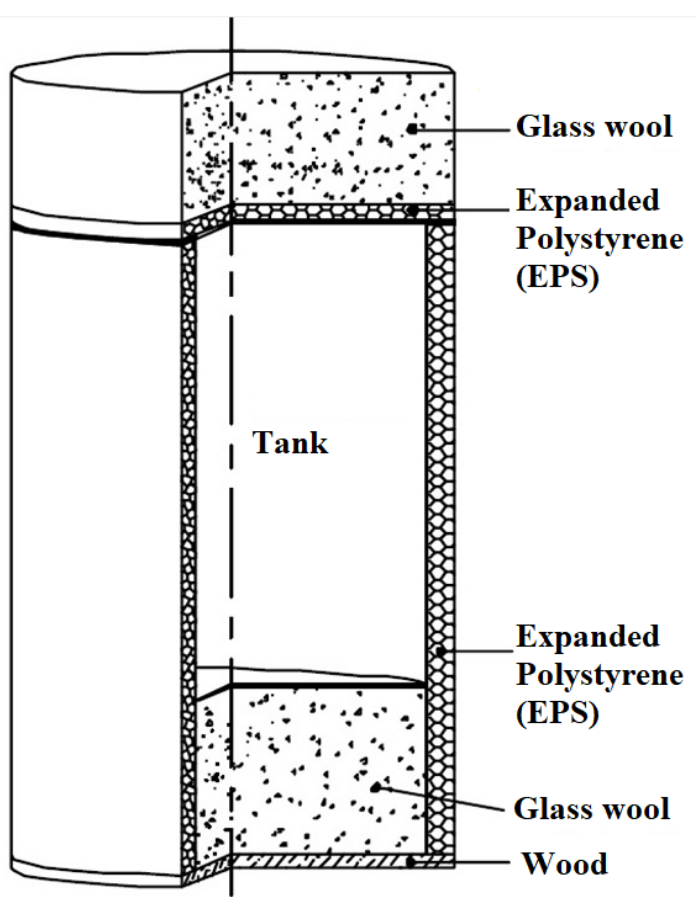

Figure 2. Angular Cut of the Tank; Source: Oliveski et al. (2000).

For the second case studied by Oliveski, Savicki (2007) presented a preliminary three-dimensional simulation using the three-dimensional computer code partially developed by him, and as a way of giving credibility to his work also compared the results obtained by him with experimental and numerical data of the work of Oliveski.ki.

\subsection{Boundary Conditional}

Table 1 shows the contour conditions adopted in this work for the second case studied by Oliveski.

Table 1. Boundary Conditional.

\begin{tabular}{|c|c|c|}
\hline \multirow{10}{*}{$\begin{array}{l}\text { Slow } \\
\text { Cooling }\end{array}$} & Flow type & Transient \\
\hline & $\begin{array}{l}\text { Buoyancy } \\
\text { model }\end{array}$ & $\begin{array}{c}\text { Boussinesq } \\
\text { Approximation }\end{array}$ \\
\hline & \multicolumn{2}{|c|}{$\begin{array}{l}\text { For the other properties water was } \\
\text { considered as Newtonian fluid. }\end{array}$} \\
\hline & $\begin{array}{l}\text { Gravity (From } \\
\text { top to bottom } \\
\text { of tank) }\end{array}$ & $9,8 \mathrm{~m} / \mathrm{s}^{2}$ \\
\hline & Time step & 1s \\
\hline & \multirow{3}{*}{ Walls } & Top: Adiabatic \\
\hline & & Base: $\mathrm{h}=6\left[\mathrm{Wm}^{2} / \mathrm{K}\right]$ \\
\hline & & Lateral: $\mathrm{h}=10\left[\mathrm{Wm}^{2} / \mathrm{K}\right]$ \\
\hline & $\begin{array}{l}\text { Initial tank } \\
\text { conditions }\end{array}$ & $\begin{array}{l}\text { Null velocity field } \\
\qquad \mathrm{Ti}=82^{\circ} \mathrm{C} .\end{array}$ \\
\hline & Total time & $5 \mathrm{~h}$ \\
\hline
\end{tabular}

For the external temperature, contour condition used in the simulation, the ambient temperature was used as a function of time through the graph provided by Oliveski et. al., Figure 3 below.

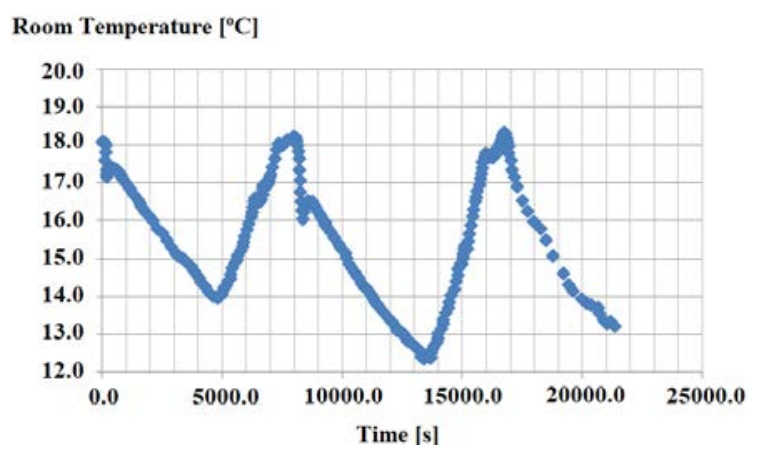

Figure 3. Surface temperature obtained experimentally.Source: Adapted, Oliveski 2000.

\subsection{Mesh}

The analyzes of mesh independence and time step performed by Adolfo were important in order to guarantee a good precision of the results sought by the author in his numerical simulation. In this way, it is known that the greater refinement of the mesh or the adoption of smaller time steps would not cause noticeable differences in results, even though they greatly increase the computational time of the simulation.

In this work the computational mesh independence study was performed using the same methodology used by Adolfo. Three meshes were used, whose characteristics are presented in Table 2. Figure 4 shows the detail image of the same.

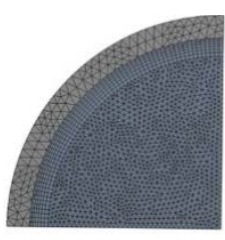

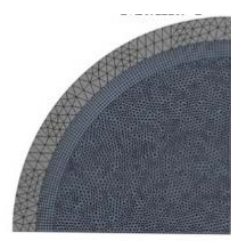

b

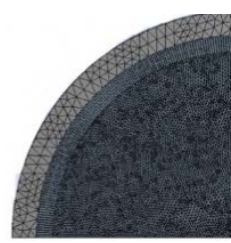

C
Figure 4. Detailing of the meshes used; (a) Mesh 0; (b) Mesh 1; (c) Mesh 2.

Table 2. Mesh Details.

\begin{tabular}{|c|c|c|c|c|c|}
\hline \multirow{5}{*}{\multicolumn{2}{|c|}{ Dimensions }} & \multicolumn{2}{|c|}{ Curvature Angle $\left({ }^{\circ}\right)$} & \multicolumn{2}{|c|}{18.0} \\
\hline & & \multicolumn{2}{|c|}{$\begin{array}{l}\text { Minimum Edge Size } \\
{[\mathrm{mm}]}\end{array}$} & \multicolumn{2}{|r|}{2.5} \\
\hline & & \multicolumn{2}{|c|}{$\begin{array}{c}\text { Max Edge Size } \\
{[\mathrm{mm}]}\end{array}$} & \multicolumn{2}{|r|}{9.8} \\
\hline & & \multicolumn{2}{|c|}{$\begin{array}{c}\text { Max Tetrahedron } \\
\text { Size }[\mathrm{mm}]\end{array}$} & \multicolumn{2}{|c|}{12.3} \\
\hline & & \multicolumn{2}{|c|}{ Growth Ratio } & \multicolumn{2}{|r|}{1.2} \\
\hline \multirow{3}{*}{\multicolumn{2}{|c|}{ Inflation }} & \multicolumn{2}{|c|}{ Thickness [mm] } & \multicolumn{2}{|c|}{20.0} \\
\hline & & \multicolumn{2}{|c|}{ Number of layers } & \multicolumn{2}{|c|}{7.0} \\
\hline & & \multicolumn{2}{|r|}{ Growth Ratio } & \multicolumn{2}{|r|}{1.2} \\
\hline \multirow{2}{*}{\multicolumn{3}{|c|}{\begin{tabular}{c|c} 
ng & Element \\
& Size $[\mathrm{mm}]$ \\
\end{tabular}}} & MESH 0 & MESH 1 & MESH 2 \\
\hline & & & 2.7 & 3.3 & 5.0 \\
\hline \multicolumn{3}{|c|}{ Total Node } & $1,512,143,0$ & $851,837.0$ & $271,898.0$ \\
\hline \multicolumn{3}{|c|}{ Total Elements } & $7,997,663.0$ & $4,379,079.0$ & $1,308,368.0$ \\
\hline
\end{tabular}

For the model of turbulence adopted, the model SST (Shear Stress Transport) was used because of the 
models of two equations more outstanding in this area, it considers in the transport of momentum the effect of the shear stress near the wall, providing a better prediction in terms of the flow detachment. In addition, this model combines the advantages of Wilcox's k - $\omega$ model (1986) and k- $\varepsilon$ model. Since the first one presents a good capacity to describe the turbulent boundary layer near the surface, where the velocities are low, for which the models based on the turbulent dissipation $(\varepsilon)$ show faults [Vergel, 2103].

\section{RESULTS AND CONCLUSION}

The simulations in total lasted approximately 58 days and the transient results at every 200 seconds of flow were saved to obtain flow properties. During the simulation, the residuals of the energy conservation equations, conservation of mass, conservation of the quantities of movement in the $\mathrm{x}, \mathrm{y}$ and $\mathrm{z}$ axes were monitored. The residue sought in the iterations was at least 0.0001 , with a maximum of 100 iterations for each time step.

By means of Figure 5 it is possible to observe the temperature profiles along the height of the tank for the time of 1 hour for the results found by Oliveski and in this work. It was observed the formation of the stratified temperature profile, as described in the work of Oliveski et al., And also that the thermal stratification occurs only in the lower region and that in the upper region the water is almost constant temperature.

For the same case studied by Oliveski, Savick (2007) analyzed the behavior of the temperature field in the tank over time, the results presented by the author for 5 h of simulation can be compared with the results of this work through Figure 6. the temperature profile of the tank remains close to that observed by Savick in this simulation. Therefore, in terms of mean temperature in the tank, the simulation is very close to the results shown by the author. However, in terms of temperature profile along the height of the tank, this behavior is somewhat different. Another fact is that observing Figure 6 it is clear that the height of the thermocline found in this simulation was considerably larger than that shown in the Savick simulation.

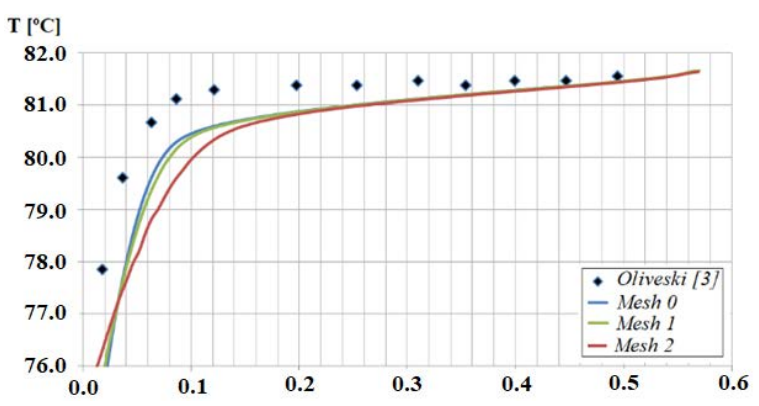

Figure 5. Comparison between the temperature profiles along the tank height for 1 hour, found by the authors.

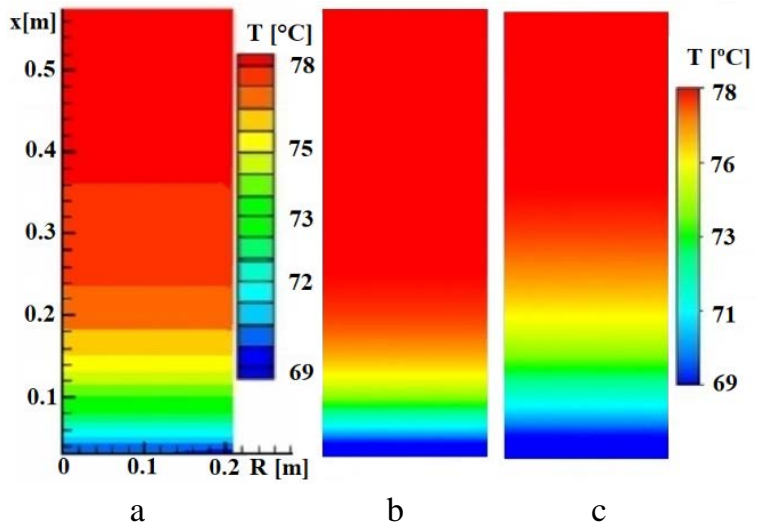

Figure 6. Comparison between the temperature profiles along the tank height for 1 hour, found by the authors.

By means of this research it was possible to estimate and verify the behavior of the storage tank, and to compare them with experimental results by Oliveski (2000) and numerical results presented by Savicki.

Through the simulations carried out it was found that the distance from the lower temperatures from the bottom of the tank to the top of the tank is less smooth than the results found by Savicki and Oliveski.

It is still worth noting that two considerations about the numerical model chosen become important, the main one being the mesh size. Such refinement levels were used for this work because the laboratory has a machine with $8 \mathrm{~GB}$ of RAM. The second is that through the study done it was possible, according to the experimental results presented by Oliveski, to validate the analysis performed and through numerical results, presented by Savicki, confirm that the mesh with the second level of refinement is already sufficiently capable of generate satisfactory results and it is therefore more suitable for generating results than the mesh with the highest degree of refinement, since the latter would cause a much greater computational effort for a non-significant difference in relation to the results found.

\section{ACKNOWLEDGEMENTS}

The authors would like to thank the National Council for Scientific and Technological Development (CNPq), projects no 460258/2014-1

\section{REFERENCES}

Adolfo, C., 2015, Simulação Numérica de um Tanque de Armazenamento de Calor de um Condicionador de Ar por Adsorção Solar, Master Thesis, UFPB, João Pessoa, PB. (in Portuguese)

Barbosa, F. F., 2013, Análise Computacional de Central de Água Gelada com Tanque de Termoacumulação, Bachelors Dissertation, UNB, 
Brasília, DF. (in Portuguese)

Evans, L. B., Reid, R. C., and Drake, E. M., 1967, Transient Natural Convection in a Vertical Cylinder, AIChE Journal, Vol. 14, No. 2, pp. 251259.

Foust, A. S., Wenzel, L. A., Clump, C. W., Maus, L., and Andersen, L. B.,1980, Principles of Unit Operations, 2nd Edition, John Wiley \& Sons, NY.

Guo, K., and Wu, S. T., 1985, Numerical Study of Flow and Temperature Stratifications in a Liquid Thermal Storage Tank, Journal of Solar Energy Engineering, Vol. 107, No.1, pp.15-20.

Ievers, S., and Li, W., 2009, Numerical Simulation of Three-Dimensional Flow Dynamics in a Hot Water Storage Tank, Applied Energy, Vol. 86, No. 12, pp. 2604-2614.

Incropera, F. P., Dewitt, D. P., Bergman, T. L., and Lavine, A. S., 2008, Fundamentos de Transferência de Calor e Massa, 6nd Edition, LTC.

Ismail, K. A. R., Leal, J. F. B., and Zanardi, M. A., 1996, A Two-Dimensional Model for Liquid Storage Tanks, Heat Transfer, Vol. 96, pp. 473-482.

Kendil, F. Z., Danciu, D. V., Schmidtke, M., Salah, A. B., Lucas, D., Krepper, E., and Mataoui, A., 2012, Flow Field Assessment Under a Plunging Liquid Jet, Progress in Nuclear Energy, Vol. 56, pp. 100-110.

Kleinbach, E. M., Beckman, W. A., and Klein, S. A., 1993, Perfomance Study of One-Dimensional Models for Stratifield Thermal Storage Tanks, Solar Energy, Vol. 2, No. 2, pp. 155-166.

Oliveira, S. R., 2004, Aplicação da Técnica de Elementos Finitos na Estratificação de Armazenadores Térmicos com Barreiras de Meios Porosos, Master Thesis, Faculdade de Engenharia da UNESP, Bauru, SP. (in Portuguese).

Oliveski R. C., Vielmo H. A., and Krenzinger, A., 2003, Cooling of Cylindrical Vertical Tanks Submitted to Natural Internal Convection, International Journal of Heat and Mass Transfer, Vol. 46, pp 2015-2026.

Oliveski, R. C., 2000, Análise Numérica e Experimental dos Campos de Temperatura e Velocidade em Armazenadores Térmicos, Doctoral Thesis, Escola de Engenharia da Universidade Federal do Rio Grande do Sul, RS.(in Portuguese).

Patankar, S.V., 1980, Numerical Heart Transfer and Fluid Flow, Hemisphere Publishing Corporation, USA.

Pentagna, R. P. P, Padilha, A., and Scalon, V. L., 2003, Estudo da Recuperação do Calor Dissipado pelo Condensador de um Refrigerador Doméstico, Mecânica Computacional Vol. XXII, Bahía Blanca, Argentina. (in Portuguese).

Riffel, D. B., 2008, Estudo Teórico e Experimental da Dinâmica e da Otimização de Refrigeradores Térmicos por Adsorção, Doctoral Thesis, UFPB, João Pessoa, PB. (in Portuguese)

Rosen, M. A., 2001, The Exergy of Stratified
Thermal Energy Storages, Solar Energy, Vol. 71, No. 3, pp. 173-185.

Savicki, D. L., 2007, Análise Numérica Tridimensional e Investigação Experimental do Comportamento Térmico e Hidrodinâmico de Reservatórios Térmicos Cilíndricos, Doctoral Thesis, UFRGS, Porto Alegre, RS. (in Portuguese)

Siqueira, D. A., 2014, Aplicação da Fluidodinâmica Computacional na Avaliação dos Efeitos Associados à Ruptura de Tubo de Trocador de Calor, Master Thesis, COPPE-UFRJ, Rio de Janeiro, RJ. (in Portuguese).

Tiba, C., 2000, Atlas Solarimétrico do Brasil, Editora Universitária da UFPE. (in Portuguese)

Truman, C. R., Wildin, M. W., 1989, Finite Difference Model for Heat Transfer in a Stratified Thermal Energy Storage Tank with Throughflow, Numerical Heat Transfer with Personal Computers and Supercomputing, ASME HTD, Vol. 110, pp. 4555.

Vergel, J. L. G., 2013, Estudo da Influência da Malha Computacional, Modelos de Turbulência e Aspectos Numéricos da Modelagem CFD em Impelidores PBT usando Malhas Não-estruturadas, Master Thesis, UNICAMP, Campinas, SP. (in Portuguese).

Vieira, C. B., 2010, Simulação Computacional da Convecção Natural em Cavidades Contendo um Fluido com Geração Interna de Calor, Master Thesis, COPPE-UFRJ, Rio de Janeiro, RJ.(in Portuguese). 